\title{
Risk Tabanlı Smart Beta Stratejilerin Borsa İstanbul'da Uygulanması
}

\author{
Selim Baha YILDIZ*
}

\begin{abstract}
$\ddot{O} Z$
Bu çalışmada 2013-2018 yılları arasında piyasa değeri ă̆ırlıklı hesaplanan BíST 30 Endeksinin getiri-risk performansı ile endeks içindeki hisse senedi ă̆ırlıklarının risk tabanlı (Minimum Varyans - Eşit Risk Katkılı - Maksimum Çeşitlendirilmiş) ve eşit ağırlıkl stratejilere göre belirlendiği portföylerin performanslarının karşılaştırılması yapılmıştır. Oluşturulan stratejilerin hepsinin yıllıklandırılmış getirisi kıyaslama ölçütü kabul edilen BiST 30 Endeksinin getirisine göre üç kattan daha fazla bulunmuştur. Benzer şekilde tüm stratejilerin yıllıklandırılmış riski kıyaslama ölçütüne göre daha düşük düzeydedir. İnceleme dönemi boyunca portföyünde bankacılık hisse senedi ă̆ırlı̆̆ az olan Maksimum Çeşitlendirilmiş Strateji getiri açısından, Minimum Varyans Stratejisi ise risk açısından diğer incelenen portföylere göre daha iyi performans sergilemişlerdir.
\end{abstract}

Anahtar Kelimeler: Smart Beta, Minumum Varyans Strateji, Eşit Risk Katkılı Strateji, Maksimum Çeşitlendirilmiş Strateji

JEL Sinıflandırması: G11

\section{Application of Risk-Based Smart Beta Strategies in Borsa İstanbul}

\begin{abstract}
This study compares the return-risk performance of the BIST 30 Index, for which weighted market value was computed for the 2013-2018 period, and the performance of portfolios, for which the weights of the stocks in the index were determined according to risk-based (Minimum VarianceEqual Risk Contribution - Maximum Diversification) and equally weighted strategies. The annualized returns of all the devised strategies were found to be more than three times the return of the BIST 30 Index as the benchmark. Similarly, the annualized risk for all strategies is lower than the benchmark. Throughout the study period, Maximum Diversification Strategy with a low weight of banking stocks in its portfolio outperformed the other portfolios under study in terms of returns, while Minimum Variance Strategy outperformed them in terms of risk.
\end{abstract}

Key Words: Smart Beta, Minumum Variance Strategy, Equal Risk Contribution Strategy, Maximum Diversification Strategy

JEL Classification: G11

\section{GíRiş}

Optimal yatırım stratejileri oluşturmak modern finansın temel konularından biridir. Markowitz'in (1952) ortalama-varyans modeline dayanan öncü çalışması ve Sharpe (1964), Lintner (1965) ve Mossin (1966) tarafindan, bu model üzerine inşa edilen finansal varlıkları fiyatlama modeli kullanılarak finans dünyasında birçok strateji geliştirilmiş ve çok sayıda akademik çalışma yapılmıştır.

\footnotetext{
*Dr. Öğretim Üyesi, Manisa Celal Bayar Üniversitesi İşletme Fekültesi, İşletme Bölümü. baha.yildiz@cbu.edu.trl, ORCID: 0000-0002-0750-0556
} 
Portföy yönetiminde uzun yıllar boyunca pasif ve aktif yatırım stratejileri kullanılmıştır. Pasif yatırım stratejisinde gösterge bir endeks baz alınır, maliyeti düşük olsa da iyi, kötü ayrımı yapmadan bütün hisselere yatırım yapılır ve karşılığında ise alınan getiri "beta" olarak tanımlanan ortalama piyasa getirisidir. Aktif yatırım stratejisinde ise sık sık ve kapsamlı olarak portföyler değiştirilerek alfa yani piyasanın üzerinde mutlak getiri elde edilmesi hedeflenmektedir. Ancak alım satım maliyetlerinin yüksek oluşu ve devir hızının fazlalığı nedeniyle portföy yöneticilerinin bir çoğunun piyasa getirisinin altında performans gösterdikleri görülmektedir

Son yıllardaki küresel piyasalardaki şiddetli dalgalanmalar ve belirsiz ekonomik durumlar yatırımcıları geleneksel yöntemlerin dışında yeni alternatiflere yöneltmiştir. $\mathrm{Bu}$ alternatifler arasında ön plana çıkan Smart Beta (Akıllı Beta) stratejilerdir. Millet (2015) Smart Beta’yı piyasa değerine göre ağırlıklandırılmaya dayanmayan, hisse ağırlıklarının daha farklı kriterlere göre oluşturulduğu stratejiler olarak tanımlamıştır. Tablo 1'de pasif, smart beta ve aktif stratejilerin özellikleri gösterilmiştir. Smart Beta'lar aktif stratejilere göre; yönetici ücreti, işlem maliyetleri, devir hızı ve yönetici insiyatifi açısından daha düşük; şeffaflık, likidite ve kapasite bakımından daha yüksek özelliğe sahiptirler. Smart Beta stratejiler, aktif ve pasif stratejilerin ağırlıklı olarak pozitif özelliklerini alan bir bileşim stratejisi olarak ifade edilebilinir.

Tablo 1. Pasif, Smart Beta ve Aktif Stratejilerin Özelliklerinin Karşıllaştırılması

\begin{tabular}{|c|c|c|c|}
\hline e & Pasif Strateji & Smart Beta & Aktif Strateji \\
\hline Makro Faktörlerden Etkilenme & Yüksek & Yüksek & Yüksek \\
\hline Yönetici Ücreti & Düsük & Illmbl & Yüksek \\
\hline İşlem Maliyetleri ve Devir Hızı & Düsük & Düşük & Yüksek \\
\hline Yönetici İnsiyatifi & Yok & Düşük & Yüksek \\
\hline Seffaflik & Yüksek & Yüksek & Düşük \\
\hline Likidite ve Kapasite & Yüksek & Yüksek & Dü̈sük-Ilımlı \\
\hline
\end{tabular}

Kaynak: Merrill Lynch (Hatzakis, 2017)

*Piyasa ağırlıklı endeks alınmıştır.

Uluslararası piyasalarda çoğu yatırımcının kıyaslama ölçütü olarak aldıkları endeksler piyasa değeri ağırlıklı endekslerdir (Örneğin S\&P 500, NASDAQ Composite, MSCI ACWI, FTSE 100, BİST 100/30). Ayrica bu endekslere bağlı çok sayıda endeks fonu vardır. Fakat piyasa değeri ağırlıklı endekslerin büyük çaplı ve aşırı fiyatlanmış hisselere yönelmeleri (Hsu, 2006) ve hisse ağırlıklarının riski gözetmeyip sadece fiyatlara göre belirlenmesinden dolayı ortalama-varyans etkinsizliğine yol açabilmektedir (Arnott vd., 2005). Smart Beta stratejilerin amacı belirli kurallar dahilinde piyasa değeri ağırlıklı endeks içindeki hisselerin ağırlığını değiştirerek risk-getiri açısından piyasa değeri ağırlıklı endekslerden daha iyi performans sergilemektir.

Temel mantalitesi alternatif ağırlıklandırma yöntemleri kullanarak piyasayı yenmek olan Smart Beta stratejilerde değişik kriterler baz alınarak çok sayıda portföy yapılabilir. Bunlar arasında en yoğun olarak kullanılanlar dört temel kategoriye ayrılabilir. Birincisi hisse ağırlıklarının şirketin defter değeri, satışları, kar payı, kazancı veya nakit akışı gibi temel değerlerine göre belirlendiği stratejiler, ikincisi hisse senedi ağırlıklarının değişik faktörlere (değer, büyüklük, momentum, 
kalite vb.) göre ağırlıklandırıldığı stratejiler, üçüncüsü risk tabanlı stratejiler (Tablo 2 'de stratejiler belirtilmiştir) ve sonuncusu eşit ağırlıklı stratejidir. Bunlar haricinde hisselerin getiri veya risk ölçütlerini kullanarak daha birçok strateji üretilebilinir. Tablo 2'de bu çalışmada kullanılan stratejiler gösterilmiştir.

Tablo 2. Eşit Ağırlıklı Strateji ve Risk Tabanlı Smart Beta Stratejiler

\begin{tabular}{|c|l|}
\hline Yöntem $\boldsymbol{A d \imath}$ & \multicolumn{1}{c|}{ Açıklama } \\
\hline Eşit Ă̆ırlıkı Strateji (EAS) & $\begin{array}{l}\text { Portföyün içindeki her bir hissenin ağırlığının birbirine eşit olduğu } \\
\text { model }\end{array}$ \\
\hline $\begin{array}{c}\text { Minimum Varyans Stratejisi } \\
\text { (MVS) }\end{array}$ & $\begin{array}{l}\text { Portföy riskinin minimum olmasına göre hisselerin ağırlıklarının } \\
\text { belirlendiği model }\end{array}$ \\
\hline $\begin{array}{c}\text { Eşit Risk Katkılı Strateji (ERKS) } \\
\text { Maksimum Çeşitlendirilmiş } \\
\text { Strateji (MÇS) }\end{array}$ & $\begin{array}{l}\text { Portföydeki hisselerin volatilitesinin eşit olacak şekilde hisselerin } \\
\text { ağılıklarının belirlendiği model }\end{array}$ \\
\hline $\begin{array}{l}\text { Portföydeki hisselerin çeşitlendirilmesini maksimize edecek şekilde } \\
\text { hisselerin ağırlıklarının belirlendiği model }\end{array}$ \\
\hline
\end{tabular}

Kaynak: De Carvalho, Lu ve Moulin (2012)

Geçmişi eskiye dayanan ve uygulaması basit olan eşit ağırlıklı stratejide her bir hisse senedinin ağırlı̆̆ olarak aynı ağırlığa sahiptir. Bu stratejinin arkasındaki fikir, birkaç hisse senedi etrafında ağırlık konsantrasyonunu önlemektir. DeMiguel vd. (2009) yaptıkları kapsamlı çalışmada, 7 farklı veri seti kullanarak 14 varlık dağılım modelinin performanslarını karşılaştırmışlar ve eşit ağırlık stratejisinin performansının diğer 13 stratejiye göre geri olmadığını tespit etmişlerdir. Plyakha vd. (2012) ABD hisse senetleri endeksleri için yaptıkları çalışmada; eşit, değer ve fiyat ağırlıklı hisse senedi portföylerinin performansını karşılaştırmışlardır. Eşit ağırlıklı portföyün toplam ortalama getiri, dört faktörlü alfa, Sharpe oranı açısından değer ve fiyat ağırlıklı portföylerden daha iyi performans sergilediğini bulmuşlardır.

Minimum varyans stratejisi etkin sinırın ucundaki tek bir noktadır ve buras1 portföyün riskinin minimum olduğu yerdir. Haugen ve Baker'ın (1991) çalışması MVS uygulandığı öncü çalışmalardandır. Bu çalışmada MVS'nin piyasa potföyünü yendiğini göstermişlerdir. Benzer şekilde, Clark vd. (2006) ABD hisse senesi piyasaları için yaptıkları çalışmada, minimum varyanslı porföyün piyasa değeri ağırlıklı portföye göre riski dörtde üç oranında azalttığını ve getirisinin daha fazla olduğunu bulmuşlardır.

Eşit risk katkılı stratejide ise portföyün içerisindeki hisselerin riski birbiri ile aynıdır. Maillard vd. (2010) eşit risk katkılı portföylerin minimum varyanslı ve eşit ağırlıklı portföylere göre daha çekici bir alternatif oluşturduğunu ve mutlak risk seviyesi, risk planlaması ve çeşitlendirme açısından bu iki yöntem arasında iyi bir trade-off imkanı olabileceğini ifade etmişlerdir.

Maksimum çeşitlendirme stratejisi, çeşitlendirme oranı kavramı ile birlikte ilk defa Choueifaty (2006) tarafından ortaya atılmıştır. Choueifaty (2006), yüksek çeşitlendirme oranına sahip portföylerin iyi ölçüde çeşitlendirildiğini ve bu tür portföylerin piyasa ağırlıklı portföylere etkin bir alternatif sağladığını iddia etmiştir. Choueifaty ve Coignard (2008) ise maksimum çeşitlendirilmiş portföyün piyasa ağırlıklı kıyaslama ölçütüne, eşit ağırlıklı portföye ve minimum varyanslı portföye göre daha etkin olduğunu bulmuşlardır. Benzer şekilde Choueifaty vd. (2013) MSCI Dünya Endeksini kıyaslama ölçütü olarak aldıkları çalışmalarında 
maksimum çeşitlendirilmiş portföyün diğer model portföylere göre daha iyi performans gösterdiğini tespit etmişlerdir.

Bunların yanında, Clarke vd. (2013) risk tabanlı yöntemlere analitik perspektiften bakmışlardır. Chow vd. (2011) Carhart'ın 4 faktör modelini kullanarak piyasa ağırlıklı endeks ile Smart Beta endeksleri incelemişler ve Smart Beta Endekslerin daha iyi performans gösterdiğini tespit etmişlerdir. Yüksek performansın kaynakları değer ve büyüklük faktörleri iken, risk ayarlı alfa istatistiki olarak sıfirdan farklı çıkmamıştır. Ayrıca optimize modellerin (maksimum çeşitlendirme ve minimum varyans) eşit ağırlıklı ve eşit risk ağırlıklı modeller göre üstün olmadığını tespit etmişlerdir. Benzer sonuçları de Carvalho vd. (2012) ve Chaves vd. (2011) de çalışmalarında bulmuşlardır. Cesarone ve Colucci (2015) çalışmalarında hisse senedi, tahvil ve karışık varlıklardan oluşan yatırım evreninden faydalanarak; eşit ağırlıklı, minimum risk, sermaye ve riske göre çeşitlendirilmiş portföy modellerini kıyaslamışlardır. Sonuçta hiçbir modelin birbirine net bir üstünlüğünün olmadığını ve her bir modelin farklı yatırımcı tiplerine uygun olduğunu tespit etmişlerdir. Örneğin minimum risk modelinin riskten kaçan yatırımcılara uygun iken, sermaye çeşitlendirme modelinin riski seven yatırımcılara uygun olduğunu ve riske göre çeşitlendirilmiş modelin ise ikisinin arasında 1 lımlı bir risk almayı seven yatırımcı tipine uygun olduğunu bulmuşlardır. Demey vd. (2010) DJ Euro Stoxx 50 endeksi üzerine yaptıkları çalışmada, risk tabanlı stratejilerin piyasa ağırlıklı endekse göre daha iyi performans sergilediklerini göstermişlerdir.

Bu çalışmada 2013-2018 yılları arasında piyasa değeri ağırlıklı hesaplanan BIST 30 Endeksinin getiri-risk performansı ile endeks içindeki hisse senedi ağırlıklarının risk tabanlı (MVS-ERKS-MÇS) ve eşit ağırlıklı stratejilere göre belirlendiği portföylerin performanslarının karşılaştırılması amaçlanmaktadır. Çalışmanın Smart Beta stratejilerle ilgili bilgi vermesi ve BISTT 30 hisselerinin farklı ağırlıklarla getirilerinin değerlendirmesi bakımından literatüre katkı sağlayacağ 1 düşünülmektedir. Çalışmanın bundan sonraki bölümleri ise şu şekildedir: Bölüm 2'de çalışmada kullanılan veri ve metodoloji hakkında bilgi verilecek, Bölüm 3'de ise elde edilen ampirik sonuçlar açılanacaktır. Son bölüm sonuç kısmından oluşmaktadır.

\section{METODOLOJI VE VERILER}

Bu bölümde çalışmada kullanılacak olan veri seti ve risk tabanlı smart beta (minimum varyans, eşit risk katkılı ve maksimum çeşitlendirilmiş) ve eşit ağırlıklı stratejilere ait formülüzasyonlara dair bilgiler verilecektir.

Çalışmada referans endeks olarak BİST 30 endeksi kullanılacaktır. BİST 30, endeksteki hisselerin ağılıklarının piyasa değeri ile hissenin fiili dolaşımdaki pay oranının çarpımına göre belirlendiği ve ağırlık sınırlamalı (bir hissenin ağırlı̆̆ maksimum \%10 olabilir) 30 hisseden oluşan bir endekstir. Endeksin kapsamına ilişkin olarak yılda 4 kez gözden geçirme yapılmaktadır ve yeni dönemde endekse girecek ve çıkacak hisseler belirlenmektedir. Endeks dönemleri Ocak-Mart, NisanHaziran, Temmuz-Eylül ve Ekim-Aralık olmak üzere yılın dört çeyreğini kapsamaktadır. 
Çalışma, 2013-2018 dönemi için Smart Beta stratejilere göre oluşturulan portföylerin performansını karşılaştırmaktadır. Risk tabanlı stratejiler de hisse ağırlıklarını belirlerken gerekli tek girdi tahmin süresindeki getirilerden elde edilen varyans-kovaryans (VCV) matrisidir. Tahmin süresi 60 ay olarak belirlenmiştir. Örneğin portföylerin 2013-I. çeyrekteki hisse ağırlıklarının belirlenmesinde Ocak 2008-Aralık 2012 getirileri kullanılarak VCV matrisi elde edilmiştir. Bulunan ağırlıklar 3 ay (1 çeyrek) boyunca kullanılmıştır. Kayan pencere yöntemi kullanılarak her bir çeyrekte yenilenen endeks içeriğine göre ağırlıklar tekrar hesaplanmıştır. Çalışmadaki optimizasyon problemi, doğrusal olmayan optimizasyon problemleri için en gelişmiş sayısal çözüm yöntemlerinden biri olan sıralı kuadratik programlama (SQP) metodunun Matlab gerçekleştirimi ile çözülmüştür. Hisse senedi verileri İş Yatırım'ın resmi internet sitesinden alınmıştır. BİST 30'da yer alan şirketlerin tespitinde Borsa İstanbul'un resmi internet sitesinden faydalanılmıştır. Endekslerin performans değerlendirilmesinde gerekli olan risksiz faiz oranı olarak piyasadaki gösterge tahvilin getirisi kullanılmıştır. Gösterge tahvilin faizi de tr.investing.com adresinden alınmıştır.

Aşağıda ifade edilecek Smart Beta strateji formüllerinin hepsi için geçerli olacak notasyonlar şu şekildedir: $n$ hisse senedi sayısını, $R=\left(R_{1}, R_{2} \ldots R_{n}\right)$ getiri vektörünü, $R_{i} i$ hisse senedinin getirisini, $w=\left(w_{1}, w_{2} \ldots w_{n}\right)$ endekste yer alan hisse senetlerinin ağırlık vektörünü, $w_{i} i$ hisse senedinin portföydeki ağırlığını göstermektedir. Ayrıca bütün endeks yöntemlerinde aşağıda gösterilen kısıtlar bulunmaktadır. Bunlar endeksteki hisse senetlerinin ağırlıklarının toplamı 1 ve her bir ağırlığın 0'dan az ve 0.1'den (BİST 30'a uygun olması için böyle alınmıştır) fazla olmamasıdır. Hesaplamalarda açığa satışa izin verilmemiş ve işlem maliyetleri hesaplamalara katılmamıştır.

$$
A_{0}=\left\{w \in R^{n} \mid \sum_{i=1}^{n} w_{i}=1 \text { ve } 0 \leq w_{i} \leq 0.1\right\}
$$

\section{Eşit Ağırıkı Strateji}

Portföy hisse senetlerinin eşit ağırlıkta olduğu modeldir. Portföyde bulunan büyük hisse senetlerinin etkisi azalmış, küçük hisse senetlerinin ise artmıştır. Hisselerin ağırlığ 1 şu şekilde belirlenir:

$$
w_{i}=\frac{1}{n}
$$

\section{Minimum Varyans Stratejisi}

Portföy riskinin minimum olmasına göre hisselerin ağırlıklarının belirlendiği modeldir. Bu modelin dezavantajı, bazı hisse senelerinin ağırlığının yüksek, bazılarının ise düşük olmasıdır. Bu durum konsantre (yoğunlaşmış) bir portföye yol açabilir. Matematiksel olarak şu şekilde ifade edilir:

$$
\min _{w} \sigma_{p}^{2}=w^{\prime} \sum w, w \in A_{0}
$$

burada $w^{\prime}$ ağırlık vektörünün transpozunu ve $\sum$ endeksteki hisselerin VCV matrisini göstermektedir. 


\section{Eşit Risk Katkılı Strateji}

İlk defa Qian (2006) tarafından hazırlanan eşit risk katkılı strateji, portföydeki her bir hissenin portföyün riskine eşit katkıda bulunduğu modeldir. Analitik çözüm ise Maillard vd. (2010) tarafından belirlenmiştir. $i$ varlığının marjinal risk katkısı şu şekilde hesaplanabilir:

$$
\partial_{w_{i}} \sigma_{p}=\frac{\partial \sigma_{p}}{\partial w_{i}}=\frac{\left(\sum w\right)_{i}}{\sqrt{w^{\prime} \sum w}}
$$

i. varlığın risk katkısı $\sigma_{i}(w)=w_{i} \partial_{w_{i}} \sigma_{p}$ ile belirtilir. Risk katkılarının toplamı portföyün riski görülebilir $\sigma_{p}=\sum_{i}^{n} \sigma_{i}(w)$ şeklinde gösterilir. (Detaylı bilgi için Maillard vd., 2010 bakılabilir). Eşit Risk Katkılı strateji matematiksel olarak şu şekilde ifade edilir:

$$
w_{i} \sigma_{w_{i}} \sigma_{p}=w_{j} \sigma_{w_{j}} \sigma_{p} \forall i, j
$$

$\mathrm{Bu}$ özellik ağırlıkların kolay belirlenmesi için algoritmanın modellenmesine izin verir. Ayrıca önceki eşitliklerdeki tüm sapmaların kareleri toplamı minimum olmalıdır. Amaç fonksiyonunu ise şu şekildedir:

$$
\min _{w} \sum_{i=1}^{n} \sum_{j=1}^{n}\left(w_{i}\left(\sum w\right)_{i}-w_{j}\left(\sum w\right)_{j}\right)^{2}, w \in A_{0}
$$

\section{Maksimum Çeşitlendirilmiş Strateji}

Çeşitlendirmenin faydasını maksimize edecek şekilde oluşturulan strateji türüdür. Endeks içindeki hisselerin ağırlıklarını belirlerken Choueifaty ve Coignard (2008) tarafindan tasarlanan Çeşitlendirme Oranı (ÇO) kullanılır. ÇO, endeksi oluşturan hisselerin volatilitelerinin ağırlıklı ortalamasının endeksin volatilitesine oranıdır ve matematiksel olarak şu şekilde gösterilir;

$$
\text { ÇO }=\frac{\sum_{i=1}^{n} w_{i} \sigma_{i}}{\sqrt{w^{\prime} \sum w}}
$$

Hisseler arasında mükemmel bir korelasyon (korelasyonun 1 olmas1) olmadıkça bu oran genelde 1'den büyük çıkar. Portföy oluşturulurken bu oranının maksimize edilmesi hedeflenir ve amaç fonksiyonu aşağıdaki gibi ifade edilir;

$$
\max _{w_{i}} \operatorname{C\zeta O}=\frac{\sum_{i=1}^{n} w_{i} \sigma_{i}}{\sqrt{w^{\prime} \sum w}}, w \in A_{0}
$$

\section{BULGULAR}

Smart Beta stratejilere göre oluşturulan portföylerin ve kıyaslama endeksi olarak alınan BİST 30'un inceleme dönemindeki getiri ve riskleri Tablo 1'de gösterilmiştir. İncelenen dönemin tamamında en yüksek getiriyi yıllıklandırılmış \%17,93 ile maksimum çeşitlendirilmiş strateji göstermiştir. Oluşturulan bütün stratejilerin toplam getirisi kıyaslama endeksinden yüksektir. İncelenen yıllara ayrı ayrı bakılırsa 6 yılın üçünde MÇS, ikisinde MVS ve birinde EAS diğer stratejilere karş1 üstün gelmişlerdir.

Risk açısından değerlendirme yapıldığında en düşük yıllıklandırılmış risk MVS'de, en yükseği ise kıyaslama endeksi BİST 30'da görülmüştür. Yıllar ayrı 
ayrı incelendiğinde ise 2013-17-18 yıllarında en düşük risk MVS'de tespit edilmiştir.

Tablo 3. Stratejilerin Y1llar İtibari ile Risk ve Getiri Sonuçları

\begin{tabular}{|c|c|c|c|c|c|c|c|c|c|c|}
\hline & \multicolumn{2}{|c}{ EAS } & \multicolumn{2}{c|}{ MVS } & \multicolumn{2}{c|}{ ERKS } & \multicolumn{2}{c|}{ MÇS } & \multicolumn{2}{c|}{ BIST 30 } \\
\hline Ylllar & Getiri & Risk & Getiri & Risk & Getiri & Risk & Getiri & Risk & Getiri & Risk \\
\hline $\mathbf{2 0 1 3}$ & $-8,62 \%$ & $25,00 \%$ & $\mathbf{- 6 , 1 2 \%}$ & $\mathbf{2 0 , 3 0 \%}$ & $-10,44 \%$ & $24,06 \%$ & $-12,69 \%$ & $23,53 \%$ & $-15,64 \%$ & $24,20 \%$ \\
\hline $\mathbf{2 0 1 4}$ & $\mathbf{3 0 , 7 6 \%}$ & $20,66 \%$ & $26,06 \%$ & $17,49 \%$ & $28,66 \%$ & $19,47 \%$ & $26,31 \%$ & $\mathbf{1 6 , 7 1 \%}$ & $28,75 \%$ & $23,33 \%$ \\
\hline $\mathbf{2 0 1 5}$ & $-12,94 \%$ & $14,49 \%$ & $\mathbf{- 1 2 , 0 9 \%}$ & $14,04 \%$ & $-12,96 \%$ & $\mathbf{1 3 , 8 8 \%}$ & $-14,06 \%$ & $14,12 \%$ & $-17,64 \%$ & $15,44 \%$ \\
\hline $\mathbf{2 0 1 6}$ & $15,52 \%$ & $17,64 \%$ & $12,69 \%$ & $18,37 \%$ & $14,99 \%$ & $17,43 \%$ & $\mathbf{1 7 , 7 2 \%}$ & $18,92 \%$ & $9,23 \%$ & $\mathbf{1 7 , 1 9 \%}$ \\
\hline $\mathbf{2 0 1 7}$ & $59,58 \%$ & $21,34 \%$ & $65,86 \%$ & $\mathbf{1 7 , 4 8 \%}$ & $62,67 \%$ & $19,23 \%$ & $\mathbf{7 8 , 8 9 \%}$ & $21,65 \%$ & $48,79 \%$ & $19,39 \%$ \\
\hline $\mathbf{2 0 1 8}$ & $-14,24 \%$ & $18,33 \%$ & $-10,04 \%$ & $\mathbf{1 3 , 9 0 \%}$ & $-11,78 \%$ & $16,39 \%$ & $\mathbf{- 3 , 6 1 \%}$ & $15,52 \%$ & $-19,53 \%$ & $19,28 \%$ \\
\hline Ylllık & $8,64 \%$ & $20,53 \%$ & $9,77 \%$ & $\mathbf{1 7 , 9 3 \%}$ & $8,76 \%$ & $19,48 \%$ & $\mathbf{1 1 , 5 2 \%}$ & $19,76 \%$ & $2,65 \%$ & $20,75 \%$ \\
\hline
\end{tabular}

Şekil 1'de ise oluşturulan stratejilerin ve kıyaslama endeksinin kümülatif getirileri gösterilmiştir. MÇS'nin en yüksek getiriyi kazandırdığ 1 görülmektedir. 2012'nin son günü 100 TL MÇS ile oluşturulan portföye yatırılırsa 2018'in son gününde ulaşacağ 1 değer 192,37 TL'dir, aynı dönemde BİST 30 endeksine yatırılacak $100 \mathrm{TL}$ ise sadece 117,00 TL olmuştur. Kalan üç stratejinin getiri performansları net bir şekilde kıyaslama ölçütünün üzerindedir.

Şekil 1. Oluşturulan Stratejilerin ve BİST 30 Endeksinin Kümülatif Getirileri (2013-2018)

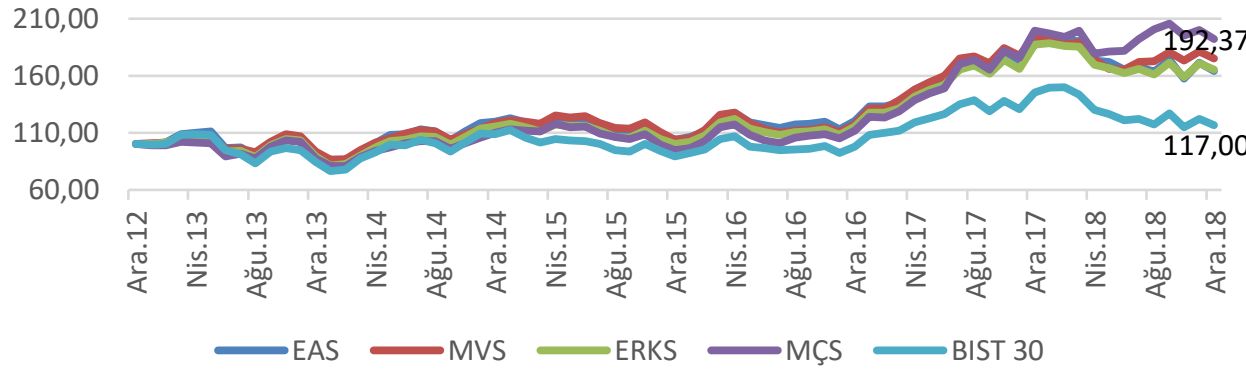

Tablo 4'de smart beta stratejileri ile oluşturulan portföylerin BİST 30 ve kendi aralarındaki korelasyon katsayıları gösterilmiştir. Genel olarak korelasyon katsayılarının çok yüksek olduğu görülmektedir. En yüksek katsayı EAS ile ERKS arasında iken en düşük katsayı MÇS ile BİST 30 arasında bulunmuştur. Fakat bu katsayı bile 0,8557 ile çok yüksektir.

Tablo 4. Korelasyon Matrisi

\begin{tabular}{|c|c|c|c|c|c|}
\hline Korelasyon & EAS & MVS & ERKS & MÇS & BIST 30 \\
\hline EAS & 1,0000 & & & & \\
\hline MVS & 0,9416 & 1,0000 & & & \\
\hline ERKS & 0,9933 & 0,9651 & 1,0000 & & \\
\hline MÇS & 0,9173 & 0,9633 & 0,9389 & 1,0000 & \\
\hline BIST 30 & 0,9719 & 0,9037 & 0,9608 & 0,8557 & 1,0000 \\
\hline
\end{tabular}


Tablo 5 oluşturulan stratejilerin riske göre ayarlanmış performans metotlarına göre bulunan değerlerini göstermektedir. Buna göre inceleme döneminde tek pozitif Sharpe oranı MÇS'de bulunmuştur. 6 yıllık süreçte risksiz faiz oranından yüksek getiri sadece MÇS'den elde edilmiştir. İzleme hatası, oluşturulan stratejilerin kıyaslama endeksini ne ölçüde yakından takip ettiğini gösterir ve en iyi ölçüm tekniği olarak portföy ile endeks getirileri arasındaki farkın standart sapması kullanılır. Buna göre en yüksek değerler MÇS ve MVS'de görülmüştür. Aktif getirinin (portföyün getirisinden kıyaslama endeksinin farkı) izleme hatasına bölünmesi ile bulunan bilgi oranına göre, bütün oluşturulan stratejiler kıyaslama endeksine göre daha iyi performans sergilemişlerdir. Maksimum düşüş ise portföyün yeni bir zirveye ulaşmadan ulaştığı tepe noktadan maksimum nereye kadar düştüğünün göstergesidir. Burada minimum kaybın düşük olması istenilen bir durumdur buna göre en düşük kayıp MVS'de en yüksek kayıp ise BIST 30 endeksinde görülmüştür. Şartlı VaR bir portföyün sahip olduğu kuyruk riski miktarını ölçen bir risk değerlendirme ölçüsüdür. Getiri dağılımında, riske maruz değer (VaR) kesinti noktasının ötesinde, aşırı zararların ağırlıklı bir ortalaması alınarak elde edilir. Buna göre uç nokta risk ortalaması en yüksek $11,10 \%$ ile MÇS'de olurken, en düşük 9,31\% ile MVS'de görülmektedir.

Tablo 5. Stratejilerin Performans Sonuçları

\begin{tabular}{|c|c|c|c|c|c|}
\hline & $\begin{array}{c}\text { Sharpe } \\
\text { Oranı }\end{array}$ & $\begin{array}{c}\text { Izleme } \\
\text { Hatası }\end{array}$ & $\begin{array}{c}\text { Bilgi } \\
\text { Oranı }\end{array}$ & $\begin{array}{c}\text { En Yüksek } \\
\text { Düşüş }\end{array}$ & Şartlı VaR \\
\hline EAS & $-0,1070$ & 0,0490 & 1,2233 & $24,75 \%$ & $11,00 \%$ \\
\hline MVS & $-0,0596$ & 0,0892 & 0,7980 & $20,33 \%$ & $9,31 \%$ \\
\hline ERKS & $-0,1068$ & 0,0577 & 1,0584 & $24,16 \%$ & $10,98 \%$ \\
\hline MÇS & 0,0345 & 0,1092 & 0,8121 & $21,70 \%$ & $11,10 \%$ \\
\hline BíST 30 & $-0,3947$ & 0,0000 & 0,0000 & $29,52 \%$ & $10,46 \%$ \\
\hline
\end{tabular}

*VaR kesinti noktası değeri 5\% alınmıştır.

Tablo 6'da stratejilerin sermaye varlıklarını fiyatlandırma modeli (CAPM), Fama-French 3 faktör modeli (FF3FM) ve Carhart 4 faktör modeline (Carhart 4FM) göre yapılan regresyon sonuçlarını göstermektedir. Portföy yöneticisinin başarısının göstergelerinden biri olan pozitif ve istatistiki açıdan anlamlı alfa, her üç modelde bütün stratejiler için pozitif bulunmuştur. CAPM'da alfaların tümü çeşitli anlamlılık düzeylerinde istatistiki açıdan anlamlı iken, FF3M'de EAS ve ERKS, Carhart 4FM'de ise sadece EAS istatistiki açıdan anlamlı bulunmuştur. Tüm modeller stratejilerin tamamında anlamlı beta üretmişlerdir. Değerlerin birden küçük olması stratejilerde defansif hisse senetlerinin ağırlığının kıyaslama endeksine göre daha fazla olduğunun göstergesidir. 
Tablo 6. CAPM, FF3FM ve Carhart 4FM Regresyon Sonuçları

\begin{tabular}{|c|c|c|c|c|}
\hline \multicolumn{5}{|c|}{ CAMP } \\
\hline Strateji & EAS & MVS & ERKS & MÇS \\
\hline Alfa & $0,45 \%^{* * *}$ & $0,41 \%^{*}$ & $0,42 \%^{* *}$ & $0,59 \%^{*}$ \\
\hline Beta & $0,9622^{* * *}$ & $0,7808^{* * *}$ & $0,9015^{* * *}$ & $0,8123^{* * *}$ \\
\hline \multicolumn{5}{|l|}{ FF3FM } \\
\hline Strateji & EAS & MVS & ERKS & MÇS \\
\hline Alfa & $0,34 \%^{* *}$ & $0,28 \%$ & $0,31 \%^{*}$ & $0,29 \%$ \\
\hline Beta & $0,9849^{* * *}$ & $0,8176^{* * *}$ & $0,9236^{* * *}$ & $0,8910^{* * *}$ \\
\hline SMB & $1,5422^{* * *}$ & $1,7490^{* * *}$ & $1,4799^{* * *}$ & $3,8177^{* * *}$ \\
\hline HML & 0,0555 & $-0,3291$ & 0,0446 & $-0,6597$ \\
\hline Strateji & \multicolumn{5}{|c|}{ Carhart 4FM } & MAS & MVS & ERKS & MÇS \\
\hline Alfa & $0,30 \% \%^{* *}$ & $0,26 \%$ & $0,28 \%$ & $0,24 \%$ \\
\hline Beta & $0,9793^{* * *}$ & $0,8153^{* * *}$ & $0,9192^{* * *}$ & $0,8845^{* * *}$ \\
\hline SMB & $1,2934^{* * *}$ & $1,6441^{* *}$ & $1,2880^{* * *}$ & $3,5264^{* * *}$ \\
\hline HML & 0,1200 & $-0,3019$ & 0,0944 & $-0,5843$ \\
\hline WML & $0,6968^{*}$ & 0,2937 & 0,5375 & 0,8156 \\
\hline
\end{tabular}

*,**,*** sirasıyla $\% 10, \% 5$ ve $\% 1$ düzeyinde anlamlıdır.

FF3F ve Carhart 4F Modellerinde her dört strateji içinde piyasa değeri küçük hisselerin getirileri büyük piyasa değerine sahip hisse senetlerine göre yüksektir ve bu pozitiflik istatistiki açıdan anlamlıdır. Diğer faktör olan defter değeri/piyasa değeri yüksek kabul edilen değer hisse senetlerinin getirileri defter değeri/piyasa küçük değere sahip büyüme hisselerinin getirileri arasındaki fark stratejileri göre farkl1lık göstermiştir. Her iki metotta da EAS ve ERKS pozitif iken, MVS ve MÇS negatif bulunmuştur. Fakat bütün değerler istatistiki açıdan anlamlı değildir. Carhart 4FM'nin son faktörü olan önceki bir yıllık süreçte kazandıran hisselerin getirisinin ayn1 dönemde kaybettirenlerin getirisine fark1 ise bütün stratejilerde pozitif bulunmuştur. İstatistiki açıdan anlamlılık sadece $10 \%$ düzeyinde EAS'de çıkmıştır. 
Şekil 2. BİST 30 ve Smart Beta Statejilere Göre Oluşturulan Portföylerin İnceleme Dönemindeki Sektör Ağırlıkları
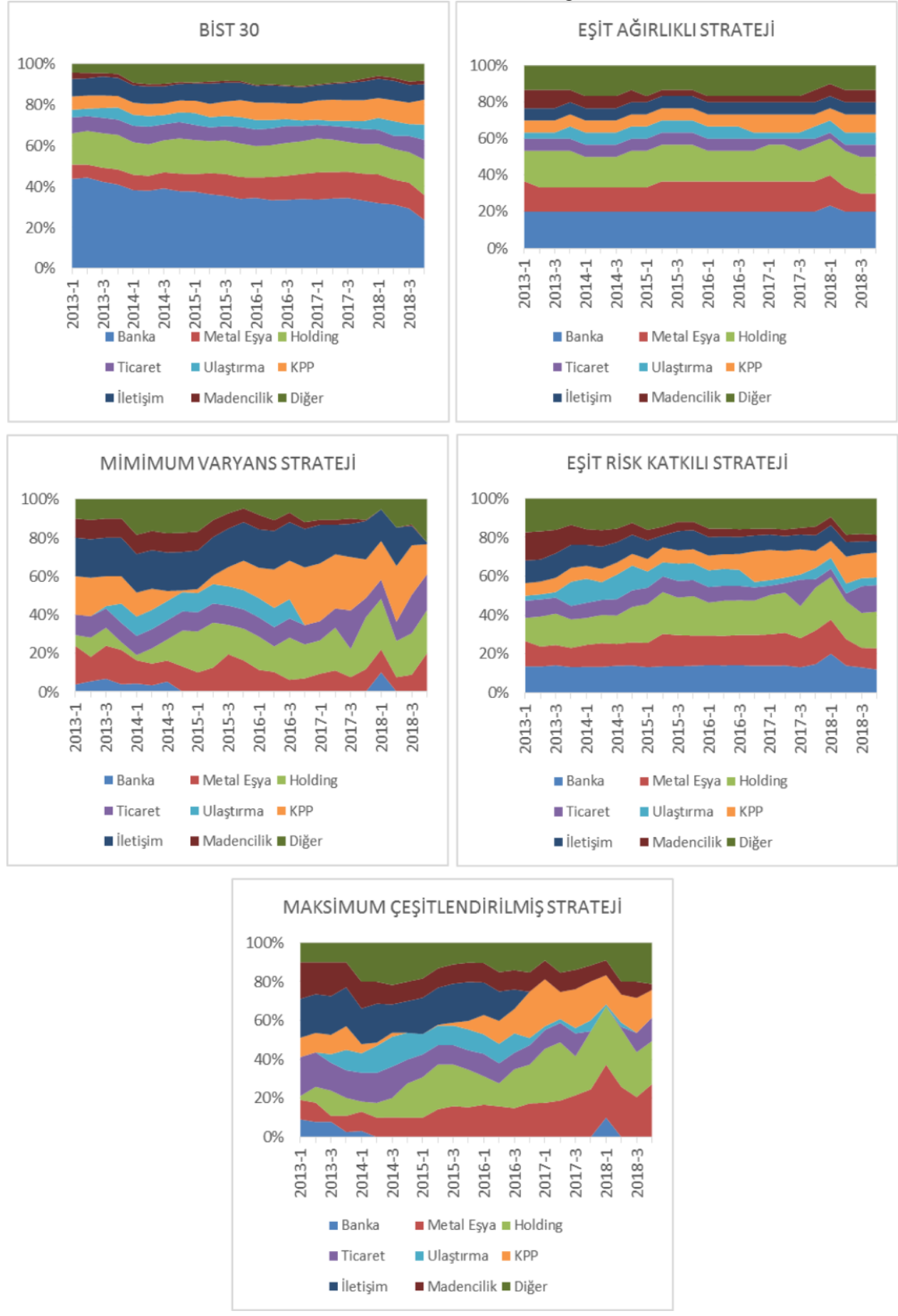
Şekil 2'de, BİST 30 endeksinin ve oluşturulan 4 strateji için inceleme döneminde portföy içeriklerindeki sektör ağırlıklarını göstermektedir. BIST 30 sektör dağılım grafiğinden Türk borsasının lokomotif sektörü olan bankacılık sektörünün ağırlı̆̆ının git gide azaldığı görülmektedir. İnceleme dönemi başında endeks içindeki ağıllığı \%45'lere yaklaşan bankacılık sektörü inceleme döneminin sonunda \%30'ların altına düşmüştür. Bu durum ilgili dönemde bankacılık sektörü getiri açısından diğer sektörlerin gerisinde kaldığını göstermektedir. Ayrıca MVS'de bankacılık sektörünün ağırlığının neredeyse sıfıra yakın olması sektörün göreceli olarak riskinin diğer sektörlere göre yüksek olduğunun göstergesidir.

Oluşturulan stratejiler için EAS'de bankacılık ve holding sektörleri portföylerdeki en yüksek ağırlığa sahiptirler. MVS'de inceleme döneminin ilk yıllarında ön plana metal eşya, kimya petrol plastik (KPP) ve iletişim sektörleri çıkarken, son yıllarda iletişim sektörünün yerini holding ve ticaret sektörleri almıştır. ERKS'de ise ilk yıllarda portföy içindeki ağırlığı yüksek olan madencilik ve iletişim sektörünün ağırlığı gitgide azalmıştır. Son olarak MÇS'de metal eşya ve holding sektörleri en yüksek ağırlığa sahiptir.

\section{SONUÇ}

Bu çalışmada 2013-2018 yılları arasında piyasa değeri ağırlıklı hesaplanan BİST 30 endeksinin getiri-risk performansı ile endeks içindeki hisse senedi ağırlıklarının risk tabanlı (MVS-ERKS-MÇS) ve eşit ağırlıklı stratejilere göre oluşturan portföylerin performansları karşılaştırılmıştır. Elde edilen sonuçlar şu şekilde siralanabilir:

- Oluşturulan dört stratejinin yıllıklandırılmış getirisi kıyaslama ölçütü olarak alınan BİST 30'dan yüksektir. En yüksek getiri performansına sahip olan MÇS'nin yıllıklandırılmış getirisi BİST 30 endeksinin yıllıklandırılmış getirisinden dört kattan fazladır.

- Yıl bazlı bakıldığında bütün stratejiler ve kıyaslama ölçütü incelenen 6 yılın yarısında pozitif getiri (2014-2016-2017), diğer yarısında negatif getiri (2013-2015-2018) performansı sergilemişlerdir. Getirinin pozitif olduğu üç yılın ikisinde MÇS'nin, negatif olduğu 3 yılın ikisinde MVS'nin diğer stratejilere göre getiri performansı daha iyidir.

- Yıllıklandırılmış riski en düşük MVS, en yüksek BİST 30 endeksi bulunmuştur. Y1l bazında ise incelenen 6 yılın üçünde en düşük risk yine MVS'de görülmüştür.

- En çok kullanılan ve bilinen riske ayarlanmış performans yöntemlerinden Sharpe Oranına göre en iyi performansı MÇS sergilemiştir. MÇS hariç diğer stratejilerin ve kıyaslama ölçütünün inceleme dönemi boyunca getirisi risksiz faiz oranının getirisinin altındadır. Bundan dolayı Sharpe Oranı sadece MÇS'de pozitif çıkmıştır.

- Oluşturulan stratejilerin getirilerinin hangi faktöre bağlı olduğunu tespit için uygulanan üç modelde de bütün stratejiler pozitif alfa üretmişlerdir. Tüm stratejiler için istatistiki açıdan anlamlı alfa CAPM'da çıkmıştır. 
- Tüm modellerde beta bire yakın ve birden küçük ve istatistiki açıdan anlamlıdır. Bu oluşturulan stratejilerde portföylerin ağırlığının defansif hisse senetlerinde olduğunu göstermektedir.

- FF3FM ve Carhart 4FM'ye göre bütün stratejilerde piyasa değeri küçük hisse senetlerinin getirisi, büyük olanlara göre fazla getirmiştir ve getiriler istatistiki açıdan anlamlıdır. Diğer yandan, defter değeri/piyasa değeri yüksek kabul edilen değer hisse senetlerinin getirileri defter değeri/piyasa küçük değere sahip büyüme hisselerinin getirileri arasındaki fark stratejileri göre farklilık göstermiştir.

- Sektörel bazda BİST 30 endeksinin ağırlı̆̆ İnceleme dönemi boyunca bankacılık sektörü getiri açısından diğer sektörlere göre geri kaldığı gibi risk açısından da diğerlerine nazaran yüksektir. Bunun sonucu olarak portföyünde bankacıllk hisse senedi ağırlığı az olan MÇS getiri açısından, MVS risk açısından diğer incelenen portföylere göre daha iyi performans sergilemişlerdir.

Risk tabanlı smart beta stratejilere göre oluşturulan portföylerin performans analizlerinin yapıldığı bu çalışmanın ülkemizde yeni yeni gelişen portföy yönetim şirketlerine ve diğer yatırım şirketlerine alternatif ürün üretme açısından faydalı olacağı düşünülmektedir. Bundan sonraki çalışmalarda farklı smart beta stratejiler, değişik endekslere uygulanıp sonuçları incelenebilinir.

\section{KAYNAKÇA}

Arnott, R. D., Hsu, J., ve Moore, P. (2005). Fundamental Indexation. Financial Analyst Journal, 61(2), 83-99.

Cesarone, F., ve Colucci, S. (2015). Minimum Risk vs. Capital and Risk Diversification strategies for portfolio construction. Capital and Risk Diversification Strategies for Portfolio Construction (January 20, 2015).

Chaves, D., Hsu, J., Li, F., ve Shakernia, O. (2011). Risk parity portfolio vs. other asset allocation heuristic portfolios. The Journal of Investing, 20(1), 108-118.

Choueifaty, Y. (2006). Methods and systems for providing an anti-benchmark portfolio. Patent number: USPTO 60/816, 276. Retrieved from https://www.google.com/patents/US7958038.

Choueifaty, Y., ve Coignard, Y. (2008). Toward maximum diversification. The Journal of Portfolio Management, 35(1), 40-51.

Choueifaty, Y., Froidure, T., ve Reynier, J. (2013). Properties of the most diversified portfolio. Journal of investment strategies, 2(2), 49-70.

Chow, T. M., Hsu, J., Kalesnik, V., ve Little, B. (2011). A survey of alternative equity index strategies. Financial Analysts Journal, 67(5), 37-57.

Clarke, R. G., De Silva, H., ve Thorley, S. (2006). Minimum-variance portfolios in the US equity market. The Journal of Portfolio Management, 33(1), 10-24.

Clarke, R., De Silva, H., ve Thorley, S. (2013). Risk parity, maximum diversification, and minimum variance: An analytic perspective. The Journal of Portfolio Management, 39(3), 39-53.

De Carvalho, R. L., Lu, X., ve Moulin, P. (2012). Demystifying equity risk-based strategies: A simple alpha plus beta description. The Journal of Portfolio Management, 38(3), 56-70.

DeMiguel, V., Garlappi, L., ve Uppal, R. (2009). How inefficient are simple asset allocation strategies. Review of Financial Studies, 22(5), 1915-1953.

Demey, P., Maillard, S., ve Roncalli, T. (2010). Risk-based indexation. Available at SSRN 1582998.

Hatzakis, E.D., (2017). Redefining Indexing Using Smart Beta Strategies. Merrill Lynch Semptember 2017 Report. 
Haugen, R. A., ve Baker, N. L. (1991). The efficient market inefficiency of capitalization-weighted stock portfolios. The Journal of Portfolio Management, 17(3), 35-40.

Hsu, J. C. (2006). Cap-weighted portfolios are sub-optimal portfolios1. Journal of Investment Management, vol.4, no.3: 1-10.

Lintner, J. (1965). The valuation of risk assets and the selection of risky investments in stock portfolios and capital budgets. Review of Economics and Statistics 47, 13-37.

Maillard, S., Roncalli, T., ve Teïletche, J. (2010). The properties of equally weighted risk contribution portfolios. The Journal of Portfolio Management, 36(4), 60-70.

Markowitz, H. (1952). Portfolio selection. The journal of finance, 7(1), 77-91.

Mossin, J. (1966). Equilibrium in a capital asset market. Econometrica 34, 768-783.

Millet, F. (2015). Smart Beta Broader than You Think. Lyxor Expert Opinion. www.lyxor.com.

Plyakha, Y., Uppal, R., ve Vilkov, G. (2012). Why does an equal-weighted portfolio outperform value-and price-weighted portfolios?. Available at SSRN 2724535.

Qian, E. (2006). On the financial interpretation of risk contribution: Risk budgets do add up. Journal of Investment Management 4, 1-11.

Roncalli, T. (2014). Introduction to Risk Parity and Budgeting. CRC Press.

Sharpe, William F., 1964. Capital asset prices: a theory of market equilibrium under conditions of risk. Journal of Finance 19, 425-442.

\section{SUMMARY}

The recent sharp fluctuations in global markets and uncertainty in the economy have driven investors toward new alternatives outside the conventional methods. Smart Beta strategies are particularly prominent among these alternatives. Smart Beta can be defined as strategies that are not based on weighting by market value, in which stock weights are determined according to different criteria. When compared to active strategies, Smart Betas offer lower manager fees, transaction costs, turnover rates, and manager's initiative and higher transparency, liquidity, and capacity. Smart Beta strategies can be defined as a composite strategy that predominantly involves the positive qualities of active and passive strategies.

Based on the primary goal of beating the market by using alternative weighting methods, Smart Beta strategies may involve diverse portfolios based on different criteria. The most common strategies can be classified under four main categories. First are the strategies where stock weights are determined according to a company's fundamental values such as book value, sales, profit shares, corporate earnings or cash flow; the second are the strategies where stock weights are determined according to various factors (value, size, momentum, quality, etc.); the third are risk-based strategies; and the fourth are equally weighted strategies. In addition, many other strategies could be developed by using stock returns or risks as criteria.

This study aims to compare the return-risk performance of the BIST 30 Index, for which weighted market value was computed for the 2013-2018 period, and the performance of portfolios, for which the weights of the stocks in the index were determined according to risk-based (Minimum Variance - Equal Risk Contribution- Maximum Diversification) and equally weighted strategies. It is believed to contribute to the literature in that it provides information about Smart Beta strategies and assesses the returns of the BIST 30 stocks by using different weights. 
The study produced the following results:

- Annualized returns of the four devised strategies are higher than that of the BIST 30 as the benchmark. The annualized return for Maximum Diversification Strategy with the highest return performance is more than four times higher than the annualized return of the BIST 30 index.

- On an annual basis, all the strategies and the benchmark generated positive returns in half of the six-year study period (2014-2016-2017) and negative returns in the other half (2013-2015-2018). When compared to the other strategies, the return performance is better for Maximum Diversification Strategy in two of the three years when the returns were positive and for Minimum Variance Strategy in two of the three years when the returns were negative.

- Minimum Variance Strategy has the lowest and the BİST 30 index has the highest annualized risk. On an annual basis, Minimum Variance Strategy presented the lowest risk in three years of the six-year study period.

- Maximum Diversification Strategy outperformed others according to the Sharpe Ratio, which is one of the most common and well-known riskadjusted performance methods. Except for the Maximum Diversification Strategy, all other strategies and the benchmark generated returns that were lower than the return of risk-free interest rate throughout the study period. Therefore, the Sharpe Ratio was only positive for the Maximum Diversification Strategy.

- All the three models applied to identify the factor that the returns of the devised strategies depended upon generated positive alpha. For all the strategies, statistical significant alpha was found in CAPM.

- In all the models, beta is close to one, smaller than one, and statistically significant. This shows that the portfolios in the devised strategies overweight defensive stocks.

- According to the Fama French 3-Factor Model and the Carhart 4-Factor Model, in all the strategies, stocks with small market value generated higher returns than those with large market value and these returns are statistically significant. On the other hand, the difference between the returns of the value stocks with high book value/market value and the growth stocks with small book value/market value differed according to the strategies.

- On a sectoral basis, the BIST 30 index is weighted toward the banking sector. Throughout the study period, the banking sector lagged behind other sectors in terms of returns and also had higher risk than the others. As a result, Maximum Diversification Strategy that underweighs banking stocks in its portfolio outperformed other portfolios under study in terms of returns, while Minimum Variance Strategy outperformed them in terms of risk.

This study that analyzes the performance of portfolios created according to risk-based smart beta strategies is believed to benefit the newly-emerging 
portfolio management companies and other investment companies in Turkey in creating alternative products. Future research may apply different smart beta strategies to different indices and analyze the results. 